J. Dairy Sci. 95:4939-4949

http://dx.doi.org/10.3168/jds.2011-5064

(C) American Dairy Science Association ${ }^{\circledR}, 2012$.

\title{
The effects of experimentally induced Escherichia coli mastitis and flunixin meglumine administration on activity measures, feed intake, and milk parameters
}

\author{
E. E. Yeiser, ${ }^{*}$ K. E. Leslie, $†$ M. L. McGilliard, ${ }^{*}$ and C. S. Petersson-Wolfe ${ }^{\star 1}$ \\ ${ }^{*}$ Department of Dairy Science, Virginia Tech, Blacksburg 24061 \\ †Department of Population Medicine, University of Guelph, Guelph, Ontario N1G 2W1, Canada
}

\begin{abstract}
The use of flunixin meglumine (FM), a nonsteroidal antiinflammatory drug, during experimentally induced Escherichia coli mastitis was evaluated. Twenty-four primiparous and multiparous lactating dairy cows were challenged with $1 \times 10^{2}$ cfu of E. coli 727 in 1 uninfected quarter. Of the $24 \mathrm{E}$. coli-challenged animals, 12 were administered FM [ECF; $100 \mathrm{mg}(2 \mathrm{cc}) / 45.5 \mathrm{~kg}$ of body weight) at the onset of clinical mastitis signs. The remaining 12 challenged cows were untreated (EC). An additional 11 cows were infused with $1 \mathrm{~mL}$ of sterile phosphate-buffered saline and served as the nonchallenged control (CTL) group. Activity measures, dry matter intake (DMI), milk production, milk bacterial counts from challenged mammary glands, and somatic cell score (SCS) were collected on all animals. Activity measurements were collected using both a behaviormonitoring system and data loggers. Activity was summarized by day (behavior-monitoring system) and in 3-h time periods (data loggers). An examination of animal activity indicated that EC and ECF cows stood more and lay less as compared with the CTL animals in the first $6 \mathrm{~h}$ after FM administration. When DMI was analyzed, CTL and ECF animals had greater DMI than the EC animals on d 1 postchallenge. However, by d 2 postchallenge, DMI for ECF and EC cows was significantly less than for the CTL cows. The ECF cows had greater milk yield than did EC animals by d 3 and 4 postchallenge, and no significant difference in yield was observed between the ECF and CTL animals. No differences in SCS were observed between the parity groups. Yet, bacterial counts in milk were greater in multiparous animals compared with the primiparous cows. Therefore, it can be concluded that $E$. coli mastitis does alter animal activity and may have a negative effect on animal well-being. However, the improvement
\end{abstract}

\footnotetext{
Received October 19, 2011.

Accepted May 8, 2012

${ }^{1}$ Corresponding author: milk@vt.edu
}

in DMI and milk production for ECF animals provides evidence for using a nonsteroidal antiinflammatory drug as supportive therapy in alleviating the adverse effects associated with E. coli mastitis.

Key words: Escherichia coli, mastitis, animal activity, nonsteroidal antiinflammatory drug

\section{INTRODUCTION}

Mastitis is defined as an inflammation of the mammary gland, which is usually caused by a bacterial infection. One of the most costly diseases affecting dairy cattle, mastitis is associated with a $\$ 200$ economic loss per clinical case (Smith and Hogan, 2001). A common cause of clinical environmental mastitis in dairy cows is Escherichia coli, which causes a host immune response and alters milk composition, causing the clinical expression of mastitis (Hogan and Smith, 2003). This type of infection causes alterations in the milk and in the physiological functioning of the animal.

Cows experience increased SCC, rectal temperature, serum cortisol levels, and decreased rumen motility during experimentally induced E. coli mastitis (Hogan et al., 1995, 1999). However, few reports have examined the physiological and behavioral changes that mastitis inflicts on animals. One study showed reduced lying behavior, eating time, and cud chewing following LPS infusion (Zimov et al., 2011). Additionally, time spent idly standing increased, and self-grooming decreased, when animals were infected with $E$. coli (Rasmussen et al., 2011). Some authors have hypothesized that such behavioral changes associated with mastitis may be attributed to the discomfort associated with the infection (Kemp et al., 2008; Leslie et al., 2010; Rasmussen et al., 2011). Although effective management and treatment protocols for mastitis have been successfully implemented, therapies to address the behavioral and physiological changes have not been well documented. The nonsteroidal antiinflammatory drugs (NSAID) have been well proven to reduce inflammation, pain, pain sensitivity, and fever (Leslie et al., 2010). There- 
fore, the use of an NSAID to counteract these negative effects of mastitis may be an appropriate treatment to recommend in a standard operating procedure. Cows that were experimentally induced with LPS or live $E$. coli, followed by the administration of an NSAID, showed decreased rectal temperatures (Anderson and Hunt, 1989; Wagner and Apley, 2004; Vangroenweghe et al., 2005; Banting et al., 2008) and restored rumen motility (Vangroenweghe et al., 2005; Banting et al., 2008) as compared with those not treated. Very few reports exist on the use of an NSAID during naturally occurring clinical mastitis. In one study from New Zealand, lactating dairy cows with mild or moderate clinical mastitis treated with an NSAID displayed reduced SCC and a decreased rate of removal from the herd following treatment (McDougall et al., 2009). The identification of behavioral changes associated with mastitis in combination with improvements following the administration of flunixin meglumine $(\mathbf{F M})$, has not been previously reported, in a non-LPS-induced model. Therefore, the objectives of the current trial were to assess the effects of FM treatment on activity measures, feed intake, milk production, colony-forming units, and SCS during experimentally induced E. coli clinical mastitis.

\section{MATERIALS AND METHODS}

\section{Animals}

Thirty-five primiparous $(\mathrm{n}=20)$ and multiparous $(\mathrm{n}=15)$ lactating dairy cows (29 Holstein, 6 Jersey), housed at the Virginia Tech Dairy Center (Blacksburg), were used in the study. Cows were housed in a freestall barn containing sawdust-bedded stalls with rubber mattresses. Stalls were bedded twice weekly. A weeklong adaptation period was used for socialization and adjustment to eating from Calan door feeders (American Calan Inc., Northwood, NH). Animals were 35 to 170 DIM (median $=117$ DIM) and were milked twice daily at 12-h intervals in a double- 8 milking parlor. All animals were treated according to the guidelines prescribed by the Institute for Animal Care and Use Committee at Virginia Tech under protocol number 10-012-DASC.

Quarter milk samples were aseptically collected at $-7,-5$, and $-3 \mathrm{~d}$ relative to intramammary challenge to determine preexisting infection status. Samples were evaluated for microbiological status and SCC to determine quarter-level infection status. Procedures regarding aseptic milk sampling and microbiological culture were followed as described previously (Hogan et al., 1999) and SCC was determined at the DHIA laboratory (United Federation DHIA, Blacksburg, VA). Mammary quarters with a preexisting IMI (2 out of 3 positive samples) were not considered for challenge. Using a random numbers generator, animals were randomly assigned to 1 of 3 treatment groups: E. coli challenged (EC; $\mathrm{n}=12$ ), E. coli challenged followed by FM treatment (ECF; Merck Animal Health, Summit, NJ; $\mathrm{n}=12)$, or saline control (CTL; $\mathrm{n}=11)$.

\section{Intramammary Challenge}

The challenge bacterium E. coli 727 was obtained from The Ohio State University and stored at $-80^{\circ} \mathrm{C}$ until needed (Hogan et al., 1995). Preparation of the challenge inoculum followed a previously published protocol (Hogan et al., 1995). In brief, before challenge, the bacteria were streaked for isolation on blood agar. Bacteria from a single colony were cultured in trypticase soy broth at $37^{\circ} \mathrm{C}$ for $24 \mathrm{~h}$. The bacterial culture was then centrifuged at $2,500 \times g$ at $4^{\circ} \mathrm{C}$ for $20 \mathrm{~min}$ to achieve a pellet of the bacterium. The pellet was diluted in PBS to achieve a final concentration of 1.0 $\times 10^{2} \mathrm{cfu} / \mathrm{mL}$. Colony-forming units of the challenge inoculum were determined by delivering two $100-\mu \mathrm{L}$ replicates of the final dilution on to the surface of a plate containing liquid MacConkey agar.

Following the morning milking and before infusion, challenge teats were cleaned with cotton swabs soaked in $70 \%$ ethanol. The 1 -mL inoculum $\left(1.0 \times 10^{2} \mathrm{cfu}\right)$ was infused into 1 randomly selected mammary quarter of the EC and ECF cows using a sterile 1-mL syringe fitted with a sterile teat cannula (Jorgensen Laboratories Inc., Loveland, CO) immediately following the morning milking. The CTL cows were infused with $1 \mathrm{~mL}$ of sterile PBS using the same procedure as described above. Teats were postdipped with a $1 \%$ iodophor teat disinfectant immediately after inoculation.

\section{Activity}

Each of the animals had a behavior-monitoring system (Afi Pedometer Plus; S.A.E. Afikim, Kibbutz Afikim, Israel) affixed to a rear leg fetlock, which collected activity data on a daily basis. Cow activity was collected between milking sessions and stored in the memory of the pedometer. The activity information collected was then transmitted at each milking through a reader box to the herd management software program (AfiFarm; S.A.E. Afikim). The behavior-monitoring system was used to obtain step activity (steps/h) between each milking session and was summarized for a daily measurement. The data loggers (HOBO Pendant G Data Logger; Onset Computer Corp., Pocasset, MA) 
were attached to the same rear leg as the behaviormonitoring system. This device measured acceleration and angle displacement on X-, Y-, and Z-axes. Through the measurements from both of these devices, activity was classified. Cow activity variables associated with the acceleration and angle displacement included lying bouts (number of times an animal changes from lying to standing) and average lying times for both left and right sides, in addition to total lying and standing time provided by the data loggers. The data loggers were set to start recording acceleration and angle displacement data upon the time of challenge with data collected every minute throughout the study. At the final sample point, the data loggers were removed and the collection of data ceased. To assess daily activity, the minute data were summarized into 3 -h time periods to coincide with milk collection time points. These values were then summed to generate daily activity.

\section{DMI}

Cows were fed approximately $45.5 \mathrm{~kg}$ of a TMR daily at $1230 \mathrm{~h}$ using an automated feed delivery system (Data Ranger; American Calan Inc.). On the following day, the refusals were removed via vacuum and weighed before the $1230 \mathrm{~h}$ feeding. A daily representative sample of the TMR was collected to determine the DM of the feed to achieve a DMI daily on each animal as described previously (Cyriac et al., 2008).

\section{Data Collection Postchallenge}

Quarter milk samples were aseptically collected from all quarters, and rectal temperatures were recorded, from all study cows at h 0, 3, 6, 9, 15, 18, 21, 24, and 36 , and d 2, 3, 4, 5, and 6 postchallenge. Clinical status of all quarters was recorded by an investigator blinded to treatment assignments among trial animals using a 5-point scale previously described by Hogan et al. (1995): $1=$ normal milk and normal quarter; $2=$ normal quarter but milk was questionable; $3=$ normal quarter but abnormal milk; $4=$ a swollen quarter and abnormal milk; and $5=$ swollen quarter, abnormal milk, and systemic signs of infection. A challenge quarter was considered clinically mastitic if the milk appearance score was $\geq 3$.

Each sample was subsequently analyzed for microbiological, SCC, and colony-forming units determination. Standard microbiologic procedures were performed to monitor bacterial presence in the gland, not only $E$. coli. Detection of E. coli 727 in challenge quarters was by duplicate in $1.0-\mathrm{mL}$ pour plates using MacConkey agar for EC and ECF animals. The total colony-form- ing units count was determined by pour plates or serial dilutions plated on MacConkey agar. Following incubation (at $37^{\circ} \mathrm{C}$ for $18 \mathrm{~h}$ ), the count was determined. The final colony-forming units count was transformed and reported as common logarithm of colony-forming units per milliliter. An infection was considered to be present if $\geq 1 \mathrm{cfu} / \mathrm{mL}$ of $E$. coli were present in 2 of 3 consecutive samples. Somatic cell counts were transformed to SCS for statistical analysis to normalize the data. Milk production data was collected for each milking (AfiMilk; S.A.E. Afikim) system.

\section{Flunixin Meglumine Injection}

At the onset of clinical signs (milk appearance score $\geq 3)$, ECF animals received a single dose of FM (2.2 $\mathrm{mg} / \mathrm{kg}$ of BW). As prescribed by the Virginia Tech Veterinary staff and the label recommendations, the FM was administered intravenously into the jugular vein to the ECF treatment group at the rate of $100 \mathrm{mg}$ (2 cc) $/ 45.5 \mathrm{~kg}$ of BW. Weight was determined on the day of challenge using scales at the milking parlor exit. Following administration of FM, the ECF treatment group received the same animal handling and management as the other treatment groups.

\section{Data Management and Statistical Analyses}

All data was stored in a database (Microsoft Access 2000 and Microsoft Excel 2007 for Windows; Microsoft Corp., Redmond, WA) until analysis, as described below. Data from the data loggers required the use of macros for the data to be descriptively analyzed, as previously described by Ledgerwood et al. (2010). Data logger information was recorded each minute and was later summarized into 3-h time periods to coincide with milk sample collection. To accurately compare the 3 treatment groups, in the lying time, standing time, and lying bouts models, periods before FM administration and after the specified label effectiveness were removed from the analysis.

The analyses of animal activity, DMI, milk production, common logarithm of colony-forming units, and SCS were performed using the PROC GLIMMIX procedure in SAS (version 9.2; SAS Institute Inc., Cary, $\mathrm{NC})$. The variables offered into the lying time and standing time and average daily steps activity models included treatment, lactation number, period or day, DIM, SCS, temperature, and covariates (at period -1), with associated interactions. Within the lying bouts model, treatment, lactation number, period, DIM, and baseline covariates were offered. The lying side preference model was offered treatment, lactation number, 
period, and the side of infection. The variables entered into the DMI model included treatment, lactation number, day, DIM, and daily total standing time, with associated interactions. The variables included into the milk production model included treatment, lactation number, day, DIM, day of challenge DIM, covariates, and associated interactions. The variables offered into the common logarithm of colony-forming units and SCS models included treatment, lactation number, hour, and DIM, with associated interactions. All variables entered into the model were removed manually by backward elimination based upon significance of the $P$-value, from highest to lowest until all variables were significant $(P \leq 0.05)$. For each model, least squares means and standard errors were determined for the significant variables. Slices were also used to determine significant days, periods, or hours within treatment interactions. Tukey adjusted $P$-values were calculated for all class variables.

\section{RESULTS}

The average number of bacteria infused at the time of challenge was $69 \pm 6 \mathrm{cfu} / \mathrm{mL}$ (range $59-74 \mathrm{cfu} / \mathrm{mL}$ ). Intramammary challenge with $E$. coli 727 resulted in $100 \%(24 / 24)$ of quarters becoming infected. Two animals (1 each in CTL and ECF groups) did not have activity data recorded beyond d 1 postchallenge, as the data logger was set to record in seconds instead of minutes, thus filling the memory capacity of the logger. These 2 animals were removed from the data analyses involving activity parameters. The CTL group contained 11 cows instead of the planned 12 due to the inability of one animal to learn the Calan door system; this animal was subsequently removed from the study despite meeting enrollment criteria.

\section{Animal Activity}

Least squares means and standard errors for lying and standing time are shown by treatment group in

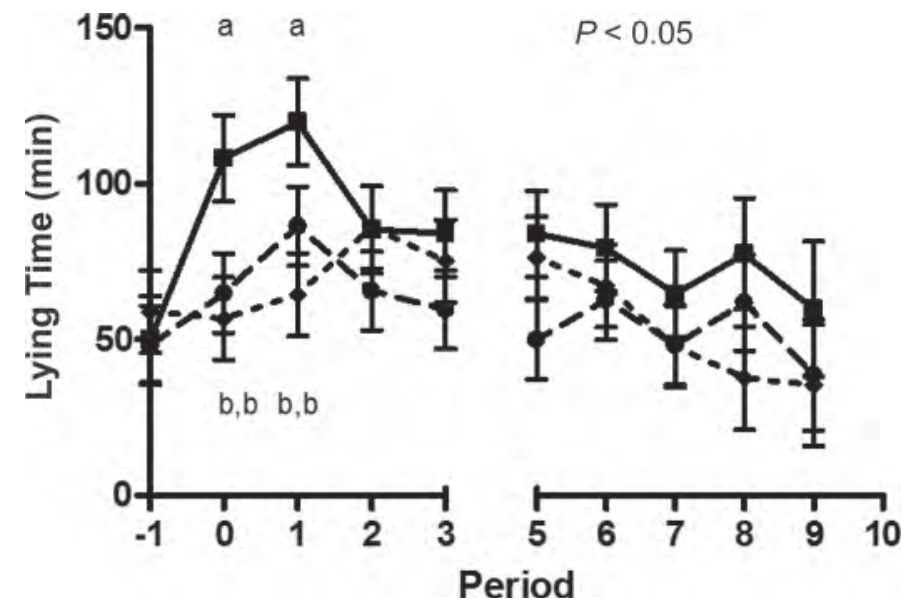

Figure 1. Effect of experimentally induced Escherichia coli mastitis on average lying time ( $\mathrm{min} / 3$-h period) in animals challenged with $E$. coli $(\bullet), E$. coli followed by flunixin meglumine treatment at the onset of clinical signs ( $\bullet$ period 0 ), or sterile saline (control, $\mathbf{\square}$ ). Error bars represent standard error of the mean. Different letters (a and $\mathrm{b}$ ) indicate significant differences between the treatment groups. Significance was declared at $P<0.05$.

Table 1. Treatment group had a significant effect on lying (Figure 1) and standing time (Figure 2). Lying time (minutes per 3-h period) was significantly reduced in periods 0 and 1 following FM injection for EC (64.8 \pm 12.7 and $86.4 \pm 12.7$ min, respectively) and ECF (56.7 \pm 13.3 and $64.4 \pm 13.3$ min, respectively) animals compared with CTL $(108.2 \pm 13.9$ and $119.9 \pm 13.9$ min, respectively) animals. Similarly, in periods 0 and 1, relative to FM injection, EC (115.2 \pm 12.7 and 93.6 \pm 12.7 min, respectively) and ECF $(123.3 \pm 13.3$ and $115.6 \pm 13.3 \mathrm{~min}$, respectively) cows spent more time standing per period than did the CTL cows (71.8 \pm 13.9 and $60.1 \pm 13.9 \mathrm{~min}$, respectively). No significant differences were seen after period 2 relative to FM administration.

The number of steps taken per hour was influenced by day relative to challenge $(P<0.05)$ but was not affected by experimental E. coli mastitis (Figure 3). Additionally, mastitis did not affect the lying side preference $(P$

Table 1. Effect of experimentally induced Escherichia coli mastitis on average lying and standing time (min/ period) in animals challenged with E. coli (EC), E. coli followed by flunixin meglumine treatment at the onset of clinical signs $(\mathrm{ECF})$, or sterile saline (control, CTL) ${ }^{1}$

\begin{tabular}{lccccc}
\hline & \multicolumn{2}{c}{ Lying time $(\min )$} & & \multicolumn{2}{c}{ Standing time $(\min )$} \\
\cline { 2 - 3 } \cline { 5 - 6 } Treatment & Mean & SE & & Mean & SE \\
\hline CTL & $78.0^{\mathrm{a}}$ & 5.9 & & $102.0^{\mathrm{a}}$ & 5.9 \\
EC & $57.4^{\mathrm{b}}$ & 5.3 & & $122.6^{\mathrm{b}}$ & 5.3 \\
ECF & $58.3^{\mathrm{b}}$ & 5.6 & & $121.7^{\mathrm{b}}$ & 5.6 \\
\hline
\end{tabular}

${ }_{\mathrm{a}, \mathrm{b}}$ Values within a column followed by different superscript letters are significantly different $(P<0.05)$.

${ }^{1}$ Each period is reflective of a 3-h block of time. The EC and ECF cows lay significantly less and stood significantly more than the CTL cows. 


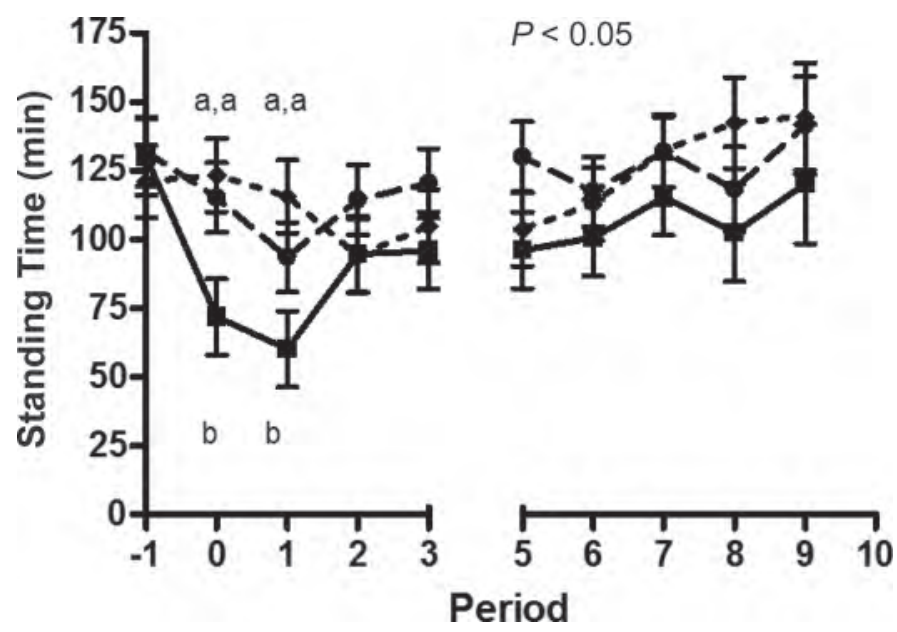

Figure 2. Effect of experimentally induced Escherichia coli mastitis on average standing time $(\mathrm{min} / 3-\mathrm{h}$ period) in animals challenged with $\operatorname{E}$. $\operatorname{coli}(\bullet)$, E. coli followed by flunixin meglumine treatment at the onset of clinical signs ( $\bullet$ p period 0 ), or sterile saline (control, $\mathbf{\square}$ ). Error bars represent standard error of the mean. Different letters (a and b) indicate significant differences between the treatment groups. Significance was declared at $P<0.05$.

$=0.39)$. As DIM at challenge increased, the number of lying bouts decreased. Furthermore, primiparous cows expressed $1.9 \pm 0.1$ lying bouts per period as compared with the multiparous animals, which showed an average of $1.6 \pm 0.1$ lying bouts $(P<0.001)$. Treatment did not influence average number of lying bouts per period following FM administration (CTL: $1.9 \pm 0.8$, EC: 1.7 \pm 0.7 , and ECF: $1.8 \pm 0.8, P=0.09)$. Similarly, the number of lying bouts did not differ between the CTL and EC groups $(1.9 \pm 0.8$ and $1.7 \pm 0.7$ per period, respectively, $P=0.08)$.

\section{Milk Production}

The treatment group by time interaction in the milk production model showed a significant effect on d 1,2, 4 , and 6 (Figure 4) among the 3 treatments. On d 1 and 2 postchallenge, the CTL group displayed greater milk yield $(32.2 \pm 2.3$ and $31.1 \pm 2.3 \mathrm{~kg}$, respectively) than the $\mathrm{EC}(16.0 \pm 2.2$ and $18.4 \pm 2.2 \mathrm{~kg}$, respectively) and $\mathrm{ECF}(17.7 \pm 2.2$ and $20.3 \pm 2.2 \mathrm{~kg}$, respectively) groups. On d 3 postchallenge, a significant difference was observed between all 3 groups, with CTL yielding $33.9 \pm 2.3 \mathrm{~kg}$, EC yielding $17.0 \pm 2.2 \mathrm{~kg}$, and ECF yielding $26.2 \pm 2.2 \mathrm{~kg}(P<0.05)$. However, by d 3 , ECF cows had a significantly higher yield $(26.2 \pm 2.2$ $\mathrm{kg})$ than the EC cows $(17.0 \pm 2.2 \mathrm{~kg})$. By d 4 and 6 postchallenge, ECF cows reached a similar milk yield $(28.74 \pm 2.2$ and $27.58 \pm 2.2 \mathrm{~kg}$, respectively) as that of the CTL cows $(34.8 \pm 2.3$ and $33.5 \pm 2.3 \mathrm{~kg}$, respectively). The milk yield of EC cows on d 4 and 6 (23.4

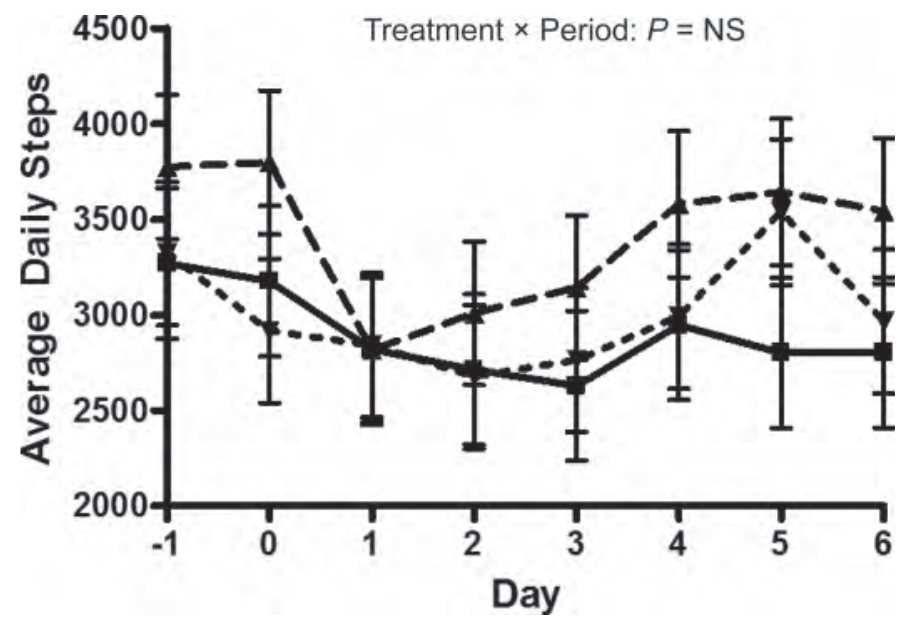

Figure 3. Effect of experimentally induced Escherichia coli mastitis on average number of steps per day in animals challenged with E. $\operatorname{coli}(\bullet), E$. coli followed by flunixin meglumine treatment at the onset of clinical signs ( ; period 0), or sterile saline (control, $\square)$. Error bars represent standard error of the mean. No significant differences between treatment groups were observed.

\pm 2.2 and $21.5 \pm 2.2 \mathrm{~kg}$, respectively, $P<0.05)$ was significantly less than that of CTL cows. On d 30,60, and 90 postchallenge, no significant difference existed among treatment groups.

Additionally, a significant effect of parity was seen on milk yield. On d 2, 3, 4, and 6 postchallenge, EC multiparous $(26.6 \pm 2.8,25.6 \pm 2.8,30.7 \pm 2.8$, and $27.7 \pm 2.8 \mathrm{~kg}$, respectively) cows produced significantly

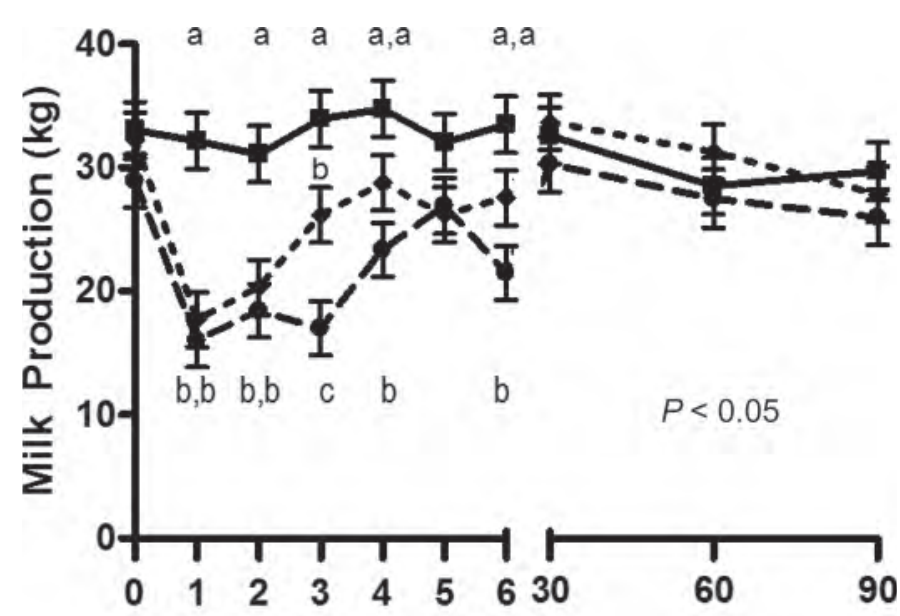

\section{Day Postchallenge}

Figure 4. Effect of experimentally induced Escherichia coli mastitis and flunixin meglumine administration on daily milk production $(\mathrm{kg})$ in animals challenged with $E$. $\operatorname{coli}(\bullet), E$. coli followed by flunixin meglumine treatment at the onset of clinical signs ( $\bullet$ ), or sterile saline (control, $\mathbf{\square})$. Error bars represent standard error of the mean. Differing letters $(\mathrm{a}-\mathrm{c})$ indicate statistical significance between treatment groups within study day. Significance was declared at $P<0.05$. 
Primiparous

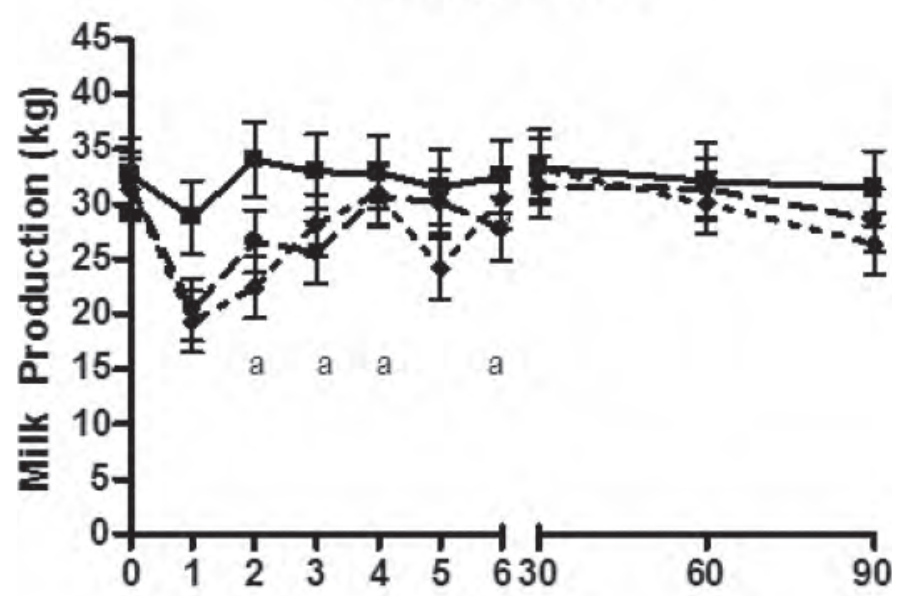

Multiparous

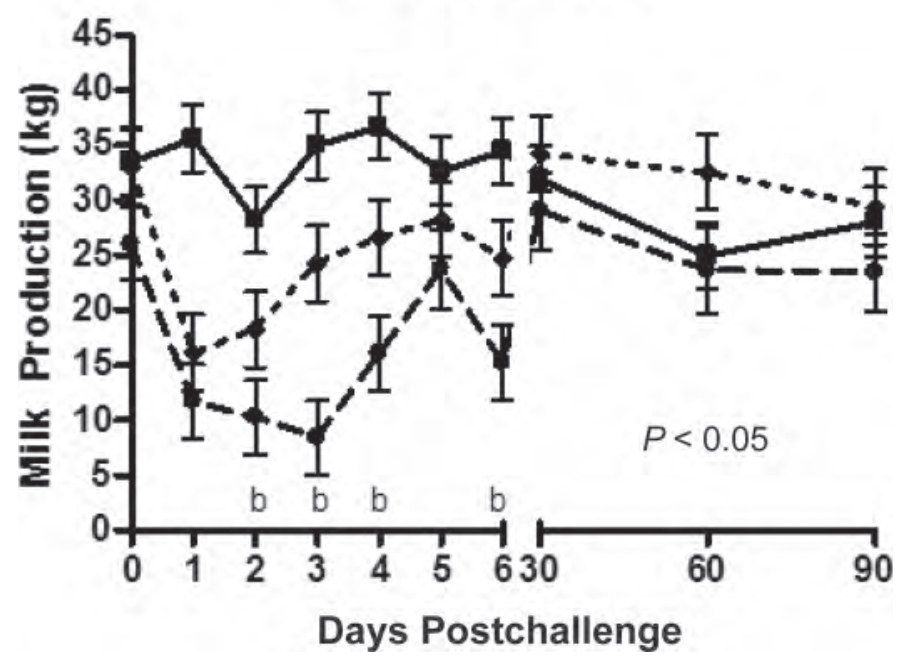

Figure 5. Effect of experimentally induced Escherichia coli mastitis and flunixin meglumine administration on daily milk production $(\mathrm{kg})$ by parity in animals challenged with $E$. coli $(\mathrm{EC} ; \bullet), E$. coli followed by flunixin meglumine treatment at the onset of clinical signs $(\bullet$ ), or sterile saline (control, $\mathbf{a})$. Error bars represent standard error of the mean. Dissimilar letters (a and b) indicate significant difference between the parity groups within study day (significance was declared at $P<0.05$ ). On d 2, 3, 4, and 6 postchallenge, EC multiparous cows produced significantly less milk than the EC primiparous cows.

less milk than the EC primiparous cows $(10.3 \pm 3.3,8.4$ $\pm 3.3,16.0 \pm 3.3$, and $15.2 \pm 3.3 \mathrm{~kg}$, respectively, $P<$ 0.05; Figure 5). However, this parity difference was not observed for the ECF or CTL cows.

\section{DMI}

On d 1 postchallenge, DM consumption was similar to $\mathrm{d} 0$ and not different between the ECF $(18.9 \pm 1.4$

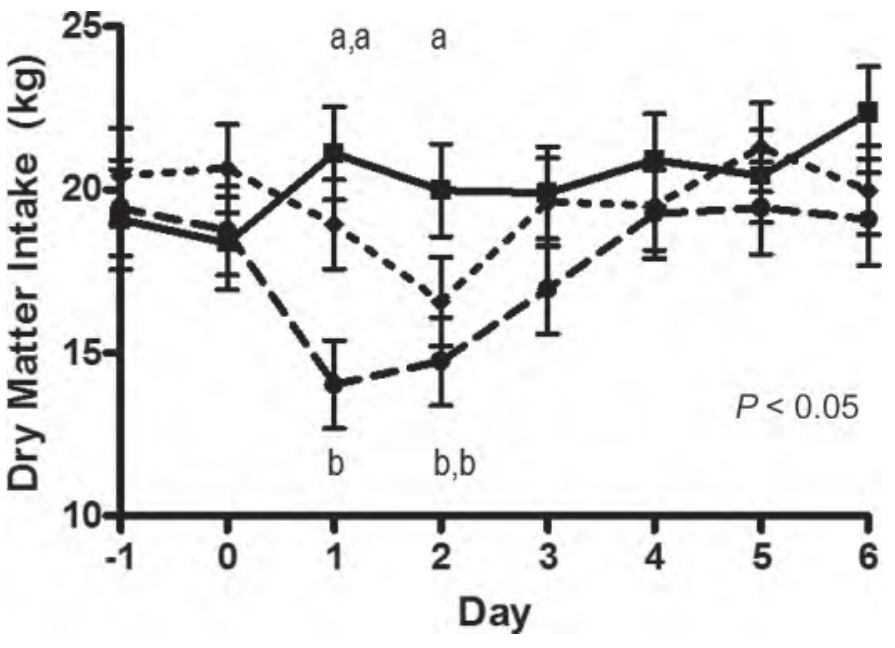

Figure 6. Effect of experimentally induced Escherichia coli mastitis and flunixin meglumine administration on DMI $(\mathrm{kg})$ in animals challenged with $E$. coli $(\bullet), E$. coli followed by flunixin meglumine treatment at the onset of clinical signs $(\bullet)$, or sterile saline (control, 口). Error bars represent standard error of the mean. Dissimilar letters ( $a$ and $b$ ) indicate a significant difference between treatment groups within study day.

$\mathrm{kg})$ and the CTL cows $(21.1 \pm 1.4 \mathrm{~kg})$. However, DMI was significantly reduced in EC animals $(14.0 \pm 1.4 \mathrm{~kg})$ compared with both ECF and CTL and compared with d 0 . On d 2 postchallenge, the CTL cows consumed more DM $(20.0 \pm 1.4 \mathrm{~kg})$ than both the EC and ECF animals $(14.7 \pm 1.4$ and $16.6 \pm 1.4 \mathrm{~kg}$, respectively, $P$ $<0.05$; Figure 6). After d 2, DMI was not significantly different among the treatment groups.

\section{Colony-Forming Units and SCS}

Administration of FM did not alter bacterial counts when compared with those from EC animals. The interaction between time and lactation number was significant $(P<0.0001$; Figure 7$)$, where multiparous animals displayed greater bacterial counts from $15 \mathrm{~h}$ through $96 \mathrm{~h}$ postchallenge, compared with the primiparous population.

A significant difference was observed between the mean $( \pm \mathrm{SE})$ SCS of the CTL animals $(2.3 \pm 0.4)$ and the EC and ECF animals $(6.6 \pm 0.4$ and $6.4 \pm 0.4$, respectively, $P<0.0001)$. The interaction of treatment by time for SCS was significant, where CTL cows had lower SCS $(P<0.0001)$ than both the EC and ECF animals from $9 \mathrm{~h}$ until the end of the trial period. No difference was seen between EC and ECF groups for SCS $(P>0.05)$. Although a significant interaction occurred between time and parity $(P=0.0004)$, the pairwise comparison showed no difference between the parities at each time point (Figure 8). Additionally, as 


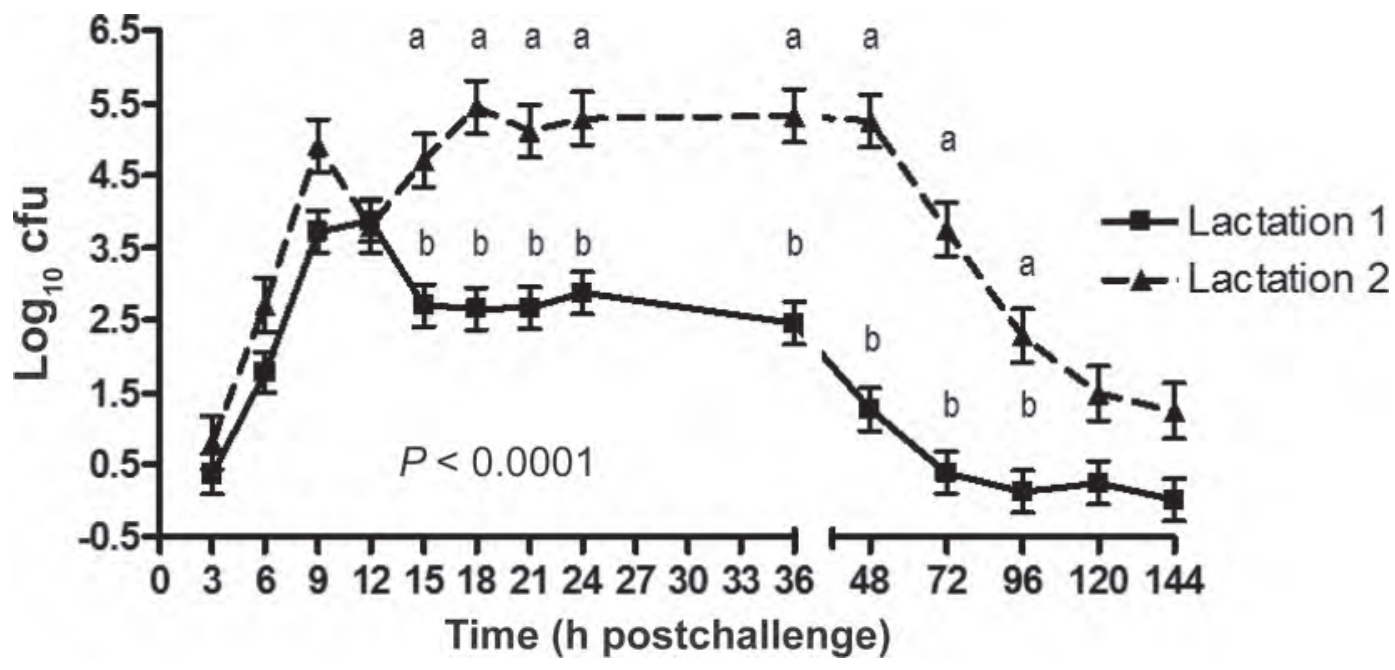

Figure 7. Effect of parity on the common logarithm of colony-forming units ( $\log _{10} \mathrm{cfu}$ ) during experimentally induced Escherichia coli mastitis. Error bars represent standard error of the mean. Dissimilar letters (a and b) indicate a significant difference between parities within period.

DIM at challenge increased, the SCS decreased (estimate $=-0.01 \pm 0.01, P=0.04)$.

\section{DISCUSSION}

A cow's behavior can be influenced by a variety of factors including environment, management, and physiologic status (Overton et al., 2002). Historically, estimates suggest a healthy cow will spend $45 \%$ of her daily time budget lying down, $55 \%$ standing, and $26 \%$ eating, with 18 to 20 resting bouts (Hedlund and
Rolls, 1977). A more recent study by Gomez and Cook (2010) reported that healthy cows spend $4.3 \pm 1.1 \mathrm{~h} / \mathrm{d}$ (17.9\%) feeding, $2.5 \pm 1.5 \mathrm{~h} / \mathrm{d}(10.4 \%)$ standing in the alley, and $2.7 \pm 2.1 \mathrm{~h} / \mathrm{d}(11.3 \%)$ standing in their stall. This leaves approximately $11.9 \pm 2.4 \mathrm{~h} / \mathrm{d}(47.5 \%)$ for resting behavior, which also includes $12.9 \pm 6.6$ lying bouts. However, disease, such as lameness or mastitis, compromises a cow's physiologic state and an alteration in behavior has been shown (Mazrier et al., 2006; Gomez and Cook, 2010). This classic sickness behavior has been described as loss of appetite, increased body

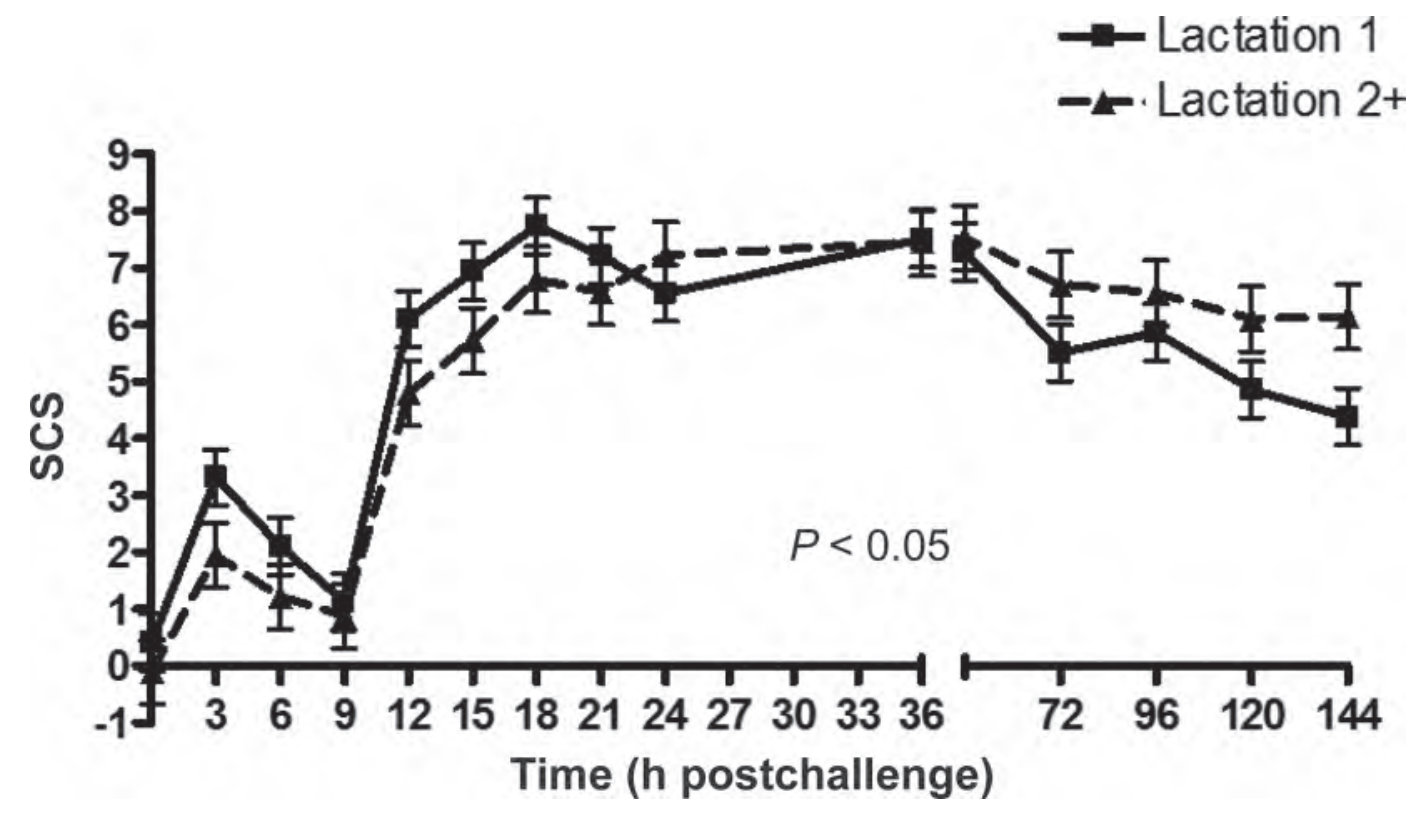

Figure 8. Effect of parity on SCS during experimentally induced Escherichia coli mastitis. Error bars represent standard error of the mean. No significant differences were observed between parity within period. 
temperature, depression, pain, lethargy, and an overall alteration in an animals' normal behavior (Leslie et al., 2010). The change in normal behavior that has been observed in animals with clinical mastitis suggests that these animals may also have reduced well-being (Leslie et al., 2010). Reducing prostaglandin production through NSAID use may result in improved well-being and altered animal behavior.

A decrease in lying behavior was shown when cows were challenged with LPS (Zimov et al., 2011). Infected animals spent $40.7 \pm 4.0 \%$ of the day lying in the stall compared with $47.9 \pm 3.4 \%$ for control animals. No improvement in lying time behavior was shown for FM-treated cows (Zimov et al., 2011). In the present study, cows infected with $E$. coli showed reduced lying time of $57.4 \pm 5.4$ and $58.3 \pm 5.6$ min per 3 -h period (EC and ECF treatments, respectively) as compared with $78.0 \pm 5.9$ min per period for the CTL animals. Similar to the Zimov et al. (2011) study, FM treatment did not affect lying time in mastitic animals. Another study found that the lying time of cows challenged with LPS was decreased from $2 \mathrm{~h}$ through $13 \mathrm{~h}$ postinfection, as compared with the day before challenge (Hänninen et al., 2007). The 2 published studies using an LPS model, along with the current study using whole-cell $E$. coli, suggest reduced lying time during experimentally induced mastitis. These deviations from normal lying behavior may be indicative of the discomfort associated with the mastitis infection. Natural sickness behavior suggests an increase in lying time and, therefore, the behavior expressed in these studies may have resulted from pain experienced.

A commonly used on-farm measurement of activity is the number of daily steps taken. In the current study, no effect of mastitis or FM treatment on daily step activity was observed, as measured by the behaviormonitoring system [as previously validated by Higginson et al. (2009)]. To our knowledge, Hänninen et al. (2007) is the only other study to analyze daily steps, and also observed no difference in the number of steps taken during an LPS challenge model.

Kikkers et al. (2006) determined that cows, which developed naturally occurring mastitis, increased their left side lying behavior with an infection on the right side, as compared with animals that were not infected. Although this observation was related to an increased probability that the cow was infected in her right side, it was not a significant relationship, which is consistent with the findings of the present study. In the current project, no relationship existed between the percent of time the cow spent lying on the uninfected side relative to the challenged quarter. This may indicate that cows do have a preference as to which side they lay upon, regardless of infection status of their mammary gland.
The E. coli infection also resulted in changes in DMI and milk production. The ECF cows consumed the same amount of DM as the CTL cows on d 1 postchallenge, and both were significantly greater than the EC cows. By d 2, however, consumption by the ECF animals was similar to the EC cows, and the CTL was significantly greater than both. In a previous study, cows that were challenged with the same strain of $E$. coli had a modest decrease of $4 \%$ in DMI on the day of challenge and returned to normal levels by d 1 to 2 postchallenge as compared with the average DMI for the $7 \mathrm{~d}$ before challenge (Todhunter et al., 1991). Similarly, Hogan et al. (1995) observed the most significant decrease in DMI on $\mathrm{d} 1$ postchallenge, with recovery occurring by $\mathrm{d} 2$. The decrease in DMI of the EC-infected cows in the current study is consistent with these findings where DMI decreased $25.1 \%$ from d 0 to 1 and returned to prechallenge levels in all groups by $\mathrm{d} 3$. Whereas the effects were more dramatic in the current study, the previous studies were conducted following J5 immunization, which likely reduced the severity of the symptoms.

In the current study, FM administration does appear to mitigate the negative effects on DMI for $1 \mathrm{~d}$ postinjection. However, this was not maintained on $\mathrm{d} 2$ postinjection. The apparent elimination half-life of FM is $8.1 \mathrm{~h}$ (Lohuis et al., 1989) as compared with carprofen, an NSAID with an apparent elimination half-life of $30.7 \mathrm{~h}$ (Vangroenweghe et al., 2005). The apparent elimination half-life of FM may explain the short-term mitigation of DMI on d 1, which was not maintained through d 2. In future studies, the evaluation of a second dose of FM for the effects on DMI is warranted. Additionally, Zimov et al. (2011) found that neither the FM treatment nor the LPS infusion affected the DMI. However, it was acknowledged that time of feeding being $2.5 \mathrm{~h}$ before the challenge may have eliminated the expected and previously observed decrease in intake, as feeding activity is highest right after feed delivery (Zimov et al., 2011).

Due to the loss of milk from treatment and decreased production, a mastitis infection is arguably the largest cost to a dairy producer (Smith and Hogan, 2001). Milk of infected animals is excluded from the rest of the sellable product until the clinical signs are no longer displayed. However, cows do not return to normal milk production levels upon the lack of clinical signs. Therefore, a lag time exists between when milk appearance returns to normal and total milk production recovery is realized. This is a period when FM treatment may have a positive effect (Anderson and Hunt, 1989; Wagner and Apley, 2004). In previous studies, cows challenged with E. coli 727 experienced a $23 \%$ (Hogan et al., 1999) and 36\% (Todhunter et al., 1991) decrease in milk production by $24 \mathrm{~h}$ postchallenge and were able 
to return to normal levels of production by d 4 to 5 without NSAID treatment. Cows challenged with LPS, however, experienced much greater losses in milk production of $74 \%$ by $12 \mathrm{~h}$ postchallenge (Anderson and Hunt, 1989). This loss can be attributed to the infusion of LPS as opposed to the live E. coli cell, as endotoxin is the actual damaging portion of $E$. coli released upon cell death from the inflammatory response (Hogan and Smith, 2003). In the present study, EC and ECF cows infected with $E$. coli had a 44.6 and $45.1 \%$ decrease in milk yield, respectively, from d 0 to 1 . Recovery of milk production levels to that of the CTL cows occurred on $\mathrm{d} 4$ for cows treated with FM (ECF). However, EC cows did not return to prechallenge milk production levels during the 7-d study period. Wagner and Apley (2004) observed that full recovery of production levels was achieved by d 10 postchallenge using FM in an LPS challenge, with some increase observed (no significance noted) by d 2 postchallenge. The dosage of FM was equivalent between that and the current study; however, our findings showed a more rapid return to preinfection yields, which could be due to the previously stated difference in the bacterial component used for infection.

Additionally, in the Wagner and Apley (2004) study, the timing of the FM administration ranged from 3 to 7 $\mathrm{h}$ postchallenge (based on clinical signs). In the current study, FM administration ranged between 18 and $24 \mathrm{~h}$ postchallenge. Clinical mastitis was defined in Wagner and Apley (2004) as a combination of increased mammary surface area and a rectal temperature of $\geq 40^{\circ} \mathrm{C}$. The current study based treatment upon clinical signs in milk appearance alone. This approach may not be as sensitive to physiological changes in the animal, hence the later FM administration time point.

Anderson and Hunt (1989) reported that cows challenged with endotoxin, followed by FM administration, were able to return to $90 \%$ of the baseline production by $24 \mathrm{~h}$ after treatment was given. Again, the bacterial component of challenge varied from the current study, and FM was administered at $2 \mathrm{~h}$ postchallenge, regardless of the expression of clinical signs of mastitis. Furthermore, 2 doses of $1.1 \mathrm{mg}$ of FM/ $\mathrm{kg}$ were administered at $\mathrm{h} 2$ and 10 postchallenge. The predefined timing of multiple doses may have allowed for the cows administered FM to return to baseline production levels, as was seen in Anderson and Hunt (1989). Additionally, DIM at the time of infection could further dictate the lasting impact on milk production. For example, cows in early lactation may be immunosuppressed, show more severe clinical symptoms, and take longer to clear the infection. The literature supports that immunosuppression causes animals to prioritize energy requirements into maintenance as opposed to a productive state (Sordillo et al., 2009). The animals used in the current study ranged in DIM from 35 to 170 DIM, with a median of 117 DIM, whereas Wagner and Apley (2004) used cows from 30 to 60 DIM, which could explain the longer lasting impact on milk production.

Previous research (Morkoç et al., 1993; Wagner and Apley, 2004; Vangroenweghe et al., 2005) has not shown a protective effect of treating mastitis with an NSAID on milk production, as seen in the current study. This difference may be largely due to the use of an LPS challenge (Morkoç et al., 1993; Wagner and Apley, 2004) as compared with a live $E$. coli model. In the live organism challenge infections, the actual level and duration of endotoxin activity in the mammary gland could be much greater and more sustained than with a specific dose of endotoxin in the LPS challenge model. Further, NSAID vary in their physiochemical characteristics, which would alter the action and efficacy. Nonsteroidal antiinflammatory drugs can selectively inhibit prostaglandin production, endoperoxides, and cyclooxygenase (COX) enzymes. Yet, it is unclear within the bovine model how that selectivity is determined (Vangroenweghe et al., 2005). Researchers have not yet determined which action would be most beneficial to block during bovine mastitis. Therefore, it is difficult to delineate which NSAID is the most appropriate in alleviating the adverse effects of $E$. coli mastitis.

In the present study, the parity by treatment by day interaction had a significant effect on milk yield. Multiparous EC cows experienced reduced milk yield throughout the week of challenge, as compared with primiparous EC animals. A parity effect was not seen in the ECF or CTL treatment, indicating that FM may have mitigated the adverse milk loss associated with the $E$. coli infection in the FM animals. The authors looked to colony-forming units and SCS as possible explanatory variables for this finding. The common logarithm of colony-forming units was significantly greater in multiparous animals throughout the challenge period. In contrast, parity by time was also significant for SCS, but no pairwise significance was observed at the same time point within parity. Furthermore, the parity by treatment by day interaction was not significant in either the common logarithm of colony-forming units or SCS models. These results indicate that although FM did not affect bacterial clearance or neutrophil recruitment, it may act upon the immune cascade associated with recognition of $E$. coli LPS, thus allowing for the improvement in milk production of the ECF animals.

Limited research has focused on explaining the parity difference in recovery from infection and disease using NSAID. In one study, no parity effect was seen when 
cows were treated for metritis with FM (Drillich et al., 2007). In another study using an LPS mastitis challenge model, Zimov et al. (2011) used both primiparous and multiparous groups of animals and reported no effect on the described results. However, others have shown that primiparous cows indeed have a stronger immune response to intramammary E. coli infections by the rapid clinical response they display when clearing the pathogen, which can be partly attributed to better neutrophil function compared with older cows (Vangroenweghe et al., 2004). Older animals display decreased neutrophil responsiveness and less superoxide anion production compared with younger cows in the first week postcalving (Gilbert et al., 1993). Additionally, it has been hypothesized that the threshold for LPS sensing is compromised in multiparous cows, which would delay the recognition of the pathogen (De Schepper et al., 2008). Each of these theories may support the increased recovery rate in primiparous milk production levels compared with the multiparous group within the animals infected with $E$. coli.

\section{CONCLUSIONS}

Escherichia coli mastitis does alter animal activity, DMI, and milk production, which are all indications that this type of infection may have a negative effect on animal well-being. In the current study, the use of the NSAID (FM) improved DMI and milk production following administration. Therefore, FM could be used as supportive therapy in alleviating some of the adverse effects associated with $E$. coli mastitis.

\section{ACKNOWLEDGMENTS}

Intervet Schering-Plough Animal Health (Kenilworth, NJ), AfiMilk (Kibbutz Afikim, Israel), the Canadian Bovine Mastitis Research Network (Saint-Hyacinthe, QC, Canada), and the Ontario Ministry of Food and Agriculture (Guelph, ON, Canada) are gratefully acknowledged for the financial support of this project. The assistance of Nuria Chapinal (University of Guelph, Guelph, ON, Canada) with the data analysis for the data logger information is greatly appreciated.

\section{REFERENCES}

Anderson, K. L., and E. Hunt. 1989. Anti-inflammatory therapy in acute endotoxin-induced bovine mastitis. Vet. Res. Commun. $13: 17-26$.

Banting, A., S. Banting, K. Heinonen, and K. Mustonen. 2008. Efficacy of oral and parenteral ketoprofen in lactating cows with endotoxin-induced acute mastitis. Vet. Rec. 163:506-509.

Cyriac, J., A. G. Rius, M. L. McGilliard, R. E. Pearson, B. J. Bequette, and M. D. Hanigan. 2008. Lactation performance of mid- lactation dairy cows fed ruminally degradable protein at concentrations lower than national research council recommendations. J. Dairy Sci. 91:4704-4713.

De Schepper, S., A. De Ketelaere, D. D. Bannerman, M. J. Paape, L. Peelman, and C. Burvenich. 2008. The toll-like receptor-4 (TLR4) pathway and its possible role in the pathogenesis of Escherichia coli mastitis in dairy cattle. Vet. Res. 39:5.

Drillich, M., D. Voigt, D. Forderung, and W. Heuwieser. 2007. Treatment of acute puerperal metritis with flunixin meglumine in addition to antibiotic treatment. J. Dairy Sci. 90:3758-3763.

Gilbert, R. O., Y. T. Grohn, P. M. Miller, and D. J. Hoffman. 1993. Effect of parity on periparturient neutrophil function in dairy cows. Vet. Immunol. Immunopathol. 36:75-82.

Gomez, A., and N. B. Cook. 2010. Time budgets of lactating dairy cattle in commercial freestall herds. J. Dairy Sci. 93:5772-5781.

Hänninen, L., J. Kaihilahti, S. Taponen, M. Hovinen, M. Pastell, and S. Pyörälä. 2007. How behaviour predicts acute endotoxin mastitis in dairy cows? Pages 157-161 in Proc. 13th Int. Congr. Anim. Hygiene. Estonian University of Life Sciences, Jõgeva Plant Breeding Institute, Estonian Research Institute of Agriculture, Tartu, Estonia.

Hedlund, L., and J. Rolls. 1977. Behavior of lactating dairy cows during total confinement. J. Dairy Sci. 60:1807-1812.

Higginson, J. H., K.E. Leslie, S.T. Millman, and D.F. Kelton. 2009. Evaluation of the Pedometry Plus system for the detection of pedometric activity and lying behaviour in dairy cattle. J. Dairy Sci. 92(E-Suppl. 1):346.

Hogan, J., and L. K. Smith. 2003. Coliform mastitis. Vet. Res. 34:507-519.

Hogan, J. S., V. L. Bogacz, M. Aslam, and K. L. Smith. 1999. Efficacy of an Escherichia coli J5 bacterin administered to primigravid heifers. J. Dairy Sci. 82:939-943.

Hogan, J. S., W. P. Weiss, K. L. Smith, D. A. Todhunter, P. S. Schoenberger, and L. M. Sordillo. 1995. Effects of an Escherichia coli J5 vaccine on mild clinical coliform mastitis. J. Dairy Sci. 78:285290.

Kemp, M. H., A. M. Nolan, P. J. Cripps, and J. L. Fitzpatrick. 2008. Animal-based measurements of the severity of mastitis in dairy cows. Vet. Rec. 163:175-179.

Kikkers, B. H., L. Ozsvari, F. J. Van Eerdenburg, A. C. Bajcsy, and O. Szenci. 2006. The influence of laterality on mastitis incidence in dairy cattle - Preliminary study. Acta Vet. Hung. 54:161-171.

Ledgerwood, D. N., C. Winckler, and C. B. Tucker. 2010. Evaluation of data loggers, sampling intervals, and editing techniques for measuring the lying behavior of dairy cattle. J. Dairy Sci. 93:5129-5139.

Leslie, K. E., C. Kielland, and S. Millman. 2010. Is mastitis painful and is therapy for pain beneficial? Pages 114-130 in Proc. National Mastitis Council, Albuquerque, NM. National Mastitis Counc., Madison, WI

Lohuis, J. A., W. Van Leeuwen, J. H. Verheijden, A. Brand, and A. S. Van Miert. 1989. Effect of steroidal anti-inflammatory drugs on Escherichia coli endotoxin-induced mastitis in the cow. J. Dairy Sci. 72:241-249.

Mazrier, H., S. Tal, E. Aizinbud, and U. Bargai. 2006. A field investigation of the use of the pedometer for the early detection of lameness in cattle. Can. Vet. J. 47:883-886.

McDougall, S., M. A. Bryan, and R. M. Tiddy. 2009. Effect of treatment with the nonsteroidal antiinflammatory meloxicam on milk production, somatic cell count, probability of re-treatment, and culling of dairy cows with mild clinical mastitis. J. Dairy Sci. 92:4421-4431.

Morkoç, A. C., W. L. Hurley, H. L. Whitmore, and B. K. Gustafsson. 1993. Bovine acute mastitis: Effects of intravenous sodium salicylate on endotoxin-induced intramammary inflammation. J. Dairy Sci. 76:2579-2588.

Overton, M. W., W. M. Sischo, G. D. Temple, and D. A. Moore. 2002. Using time-lapse video photography to assess dairy cattle lying behavior in a free-stall barn. J. Dairy Sci. 85:2407-2413.

Rasmussen, D. B., K. Fogsgaard, C. M. Røntved, I. C. Klaas, and M. S. Herskin. 2011. Changes in thermal nociceptive responses in 
dairy cows following experimentally induced Escherichia coli mastitis. Acta Vet. Scand. 53:32.

Smith, K. L., and J. S. Hogan. 2001. The world of mastitis. Page 1 in Proc. Int. Symp. Mastitis Milk Quality, Vancouver, Canada. NMC Inc., Vancouver, Canada.

Sordillo, L. M., G. A. Contreras, and S. L. Aitken. 2009. Metabolic factors affecting the inflammatory response of periparturient dairy cows. Anim. Health Res. Rev. 10:53-63.

Todhunter, D. A., K. L. Smith, J. S. Hogan, and L. Nelson. 1991. Intramammary challenge with Escherichia coli following immunization with a curli-producing Escherichia coli. J. Dairy Sci. 74:819-825.

Vangroenweghe, F., L. Duchateau, P. Boutet, P. Lekeux, P. Rainard, M. J. Paape, and C. Burvenich. 2005. Effect of carprofen treat- ment following experimentally induced Escherichia coli mastitis in primiparous cows. J. Dairy Sci. 88:2361-2376.

Vangroenweghe, F., P. Rainard, M. Paape, L. Duchateau, and C. Burvenich. 2004. Increase of Escherichia coli inoculum doses induces faster innate immune response in primiparous cows. J. Dairy Sci. $87: 4132-4144$.

Wagner, S. A., and M. D. Apley. 2004. Effects of two anti-inflammatory drugs on physiologic variables and milk production in cows with endotoxin-induced mastitis. Am. J. Vet. Res. 65:64-68.

Zimov, J. L., N. A. Botheras, W. P. Weiss, and J. S. Hogan. 2011. Associations among behavioral and acute physiologic responses to lipopolysaccharide-induced clinical mastitis in lactating dairy cows. Am. J. Vet. Res. 72:620-627. 